\title{
REFINEMENTS OF BOUNDS FOR THE FIRST AND SECOND SEIFFERT MEANS
}

\author{
Yuming CHU, BAOYU LIU AND MiaOKUN WANG
}

Abstract. In this paper, we find the greatest values $\alpha, \lambda$ and the least values $\beta, \mu$ such that the double inequalities $\alpha[5 A(a, b) / 6+H(a, b) / 6]+(1-\alpha) A^{5 / 6}(a, b) H^{1 / 6}(a, b)<P(a, b)<$ $\beta[5 A(a, b) / 6+H(a, b) / 6]+(1-\beta) A^{5 / 6}(a, b) H^{1 / 6}(a, b)$ and $\lambda[A(a, b) / 3+2 Q(a, b) / 3]+(1-$ $\lambda) A^{1 / 3}(a, b) Q^{2 / 3}(a, b)<T(a, b)<\mu[A(a, b) / 3+2 Q(a, b) / 3]+(1-\mu) A^{1 / 3}(a, b) Q^{2 / 3}(a, b)$ hold for all $a, b>0$ with $a \neq b$. Here $A(a, b), H(a, b), Q(a, b), P(a, b)$ and $T(a, b)$ denote the arithmetic, harmonic, quadratic, first Seiffert and second Seiffert means of two positive numbers $a$ and $b$, respectively.

Mathematics subject classification (2010): 26E60.

Keywords and phrases: First Seiffert means, second Seiffert mean, harmonic mean, arithmetic mean, quadratic mean.

\section{REFERENCES}

[1] B. C. CARLSon, Algorithms involving arithmetic and geometric means, Amer. Math. Monthly 78, 5 (1971), 496-505.

[2] Y. M. CHU, Y. F. QIU, M. K. WANG AND G. D. WANG, The optimal convex combination bounds of arithmetic and harmonic means for the Seiffert's mean, J. Inequal. Appl. 2010, Article ID 436457, 7 pages.

[3] C. F. Gauss, Werke, Vol. 3, 352-355, Leipzig, 1877; Werke, Vol. 10, Part 1, Leipzig, 1917.

[4] P. A. HÄsTÖ, A monotonicity property of ratios of symmetric homogeneous means, JIPAM. J. Inequal. Pure Appl. Math. 3, 5 (2002), Article 71, 23 pages.

[5] P. A. HÄstÖ, Optimal inequalities between Seiffert's mean and power mean, Math. Inequal. Appl. 7, $1(2004), 47-53$.

[6] A. A. JAGERS, Solution of Problem 887, Nieuw Arch. Wisk. (4), 12, (1994), 230-231.

[7] Y. M. LI, Y. M. CHU AND M. K. WANG, Sharp power mean bound for the Seiffert mean (submitted).

[8] H. LiU AND J.-X. Meng, The optimal convex combination bounds for Seiffert's mean, J. Inequal. Appl. 2011, Article ID 686834, 9 pages.

[9] E. Neuman And J. SÁndor, On the Schwab-Borchardt mean, Math. Pannon. 14, 2 (2003), 253-266.

[10] E. Neuman And J. SÁndor, On the Schwab-Borchardt mean II, Math. Pannon. 17, 1 (2006), 49-59.

[11] J. SÁNDOR, On certain inequalities for means III, Arch. Math. 16, 1 (2001), 34-40.

[12] J. SÁNDOR, Über zwei Mittel von Seiffert, Die Wurzel. 36, (2002), 104-107.

[13] H. J. Seiffert, Problem 887, Nieuw Arch. Wisk. (4), 11, 2 (1993), 176-176.

[14] H. J. SEIFFERT, Aufgabe $\beta 16$, Die Wurzel, 29, (1995), 221-222.

[15] H. J. SEIFFERT, Ungleichungen für einen bestimmten Mittelwert, Nieuw Arch. Wisk. (4), 13, 2 (1995), 195-198.

[16] S. S. WANG AND Y. M. CHU, The best bounds of the combination of arithmetic and harmonic means for the Seiffert's mean, Int. J. Math. Anal. 4, 22 (2010), 1079-1084.

[17] M. K. WANG, Y. F. QIU AND Y. M. CHU, Sharp bounds for Seiffert means in terms of Lehmer means, J. Math. Inequal. 4, 4 (2010), 581-586. 